\title{
Clinical Study by Intent
}

National Cancer Institute

\section{Source}

National Cancer Institute. Clinical Study by Intent. NCI Thesaurus. Code C49652.

The name of a code list that contains terms to define the type of trial, e.g. cure or prevention. 